\title{
RADENKO ŠĆEKIĆ
}

\section{Univerzitet Crne Gore}

DOI 10.5937/kultura1339245S

UDK 659.3/.4

32.019.5:324

stručni rad

\section{POLITCKKI PR,MEDINI SPNDOKTORNG}

Sažetak: Odnosi s javnošću predstavljaju sistematsku, dugoročnu aktivnost na formiranju i održavanju pozitivnog stava javnosti o nekoj ličnosti ili organizaciji, odnosno, to je djelatnost upravljanja mnjenjem, koja se fokusira na formiranje i održavanje pozitivnog ili poboljšanje lošeg imidža u javnosti. Ove aktivnosti se smatraju potrebnom u raznim oblastima ljudske djelatnosti. Definišu se kao aspekt komunikacije koji obuhvata promovisanje željenog imidža pojedinca ili grupe čiji je cilj da privuče pažnju javnosti. Izvršioci same ubjeđivačke djelatnosti su stručnjaci za persuaziju i marketing, koji oblikuju propagandne poruke i tehničko osoblje koje omogućava da se propagandna poruka uputi preko nekog od sredstava informisanja do primaoca ali to su i spin doktori. Savjetnici za imidž, politički savjetnici ali i osobe izvještene $i$ osposobljene za upravljanje informacijama i manipulacijama masovnim medijima i friziranje informacija. Poseban značaj u tome imaju agencije za odnose sa javnošću (public relations firm) koji za izvjestan honorar zastupaju interese određenog subjekta. Ove agencije koriste saznanja iz oblasti društvenih nauka, naročito psihologije i sociologije.

Ključne riječi: Politički $P R$, javno mnjenje, spin doktoring, mediji, manipulacija

Mediji su uz političke organizacije i građane jedan od aktera političke komunikacije. Uočljivi su fenomeni ogromnog uticaja medija ali i uticaja na same medije, njihova instrumentalizacija i zloupotrebe. Politički se akteri moraju koristiti medijima kako bi njihove poruke bile prenesene željenoj javnosti. Tako, vremenom, političari postaju sve više, svojevrsni glumci, koji nastoje da se u najboljem svjetlu prikažu u javnom mnjenju. 
U vezi sa pojmom javno mnenje u tijesnoj je vezi i termin odnosi s javnošć ${ }^{1}$. Odnosi s javnošću, prema Z. Slavujeviću ${ }^{2}$, predstavljaju ,sistematsku, dugoročnu aktivnost na formiranju i održavanju pozitivnog stava javnosti o nekoj ličnosti ili organizaciji, odnosno, to je djelatnost upravljanja mnenjem, koja se fokusira na formiranje i održavanje pozitivnog ili poboljšanje lošeg imidža u javnosti“.

U SAD postoje pojmovi koji su u suštini slični sa pojmom propagande u evropskom shvatanju (političko ubjeđivanje, političko komuniciranje, politički marketing). To su pojmovi: javni odnosi (public relations), političko ratovanje (politic warfare) i kontrola mišljenja (mind control) i sl. i brojne firme koje se tim poslovima bave (Public relations firms, ili skraćeno PR). Pojmovi pod ovim nazivima ne izazivaju negativno vrednovanje, čak naprotiv, ove aktivnosti se smatraju potrebnim u raznim oblastima ljudske djelatnosti (politika, ekonomija, sport i sl.). Jasno je da se ovdje ne radi samo o terminološkim razlikama već i o negiranju pojma propagande. Ideološke razlike među kandidatima na izborima u SAD su neznatne, tako da se nameće nužnost naglašavanja malih razlika, u prvom redu ličnih osobina, afiniteta i pogleda i stavova. Sa ovakvim je stilom vođenja kampanje usko povezana pojačana usredsređenost na pojedinog političara, i to ne na političara kao predstavnika neke ideologije ili stranke, nego kao "osobe". Interesantna pojava, barem u SAD, je da mediji znatno više pišu negativno o političkim kandidatima, ukazujući na njihove slabosti, propuste, nedoslednosti, a znatno manje afirmativno o njihovim idejama, programima i sl. Analizirajući taj fenomen B. Newman zaključuje da „mediji stvaraju dojam u javnosti, kao da se nužno bira manje zlo na izborima, a ne da se bira bolje rješenje“. ${ }^{3}$ I pored nesumnjive popularnosti

1 Problemi u konceptualizaciji i definisanju odnosa s javnošću potiču još od 1923. godine i predavanja i prvog priručnika o public relations (izraz koji se može prevesti kao odnosi s javnošću) Edvarda L. Bernajsa "Kristalizacija javnog mnenja (Cristallizing Public Opinion)" na prvom kursu za odnose s javnošču Univerziteta u Njujorku posvećenog toj profesiji. Osim međunarodnog termina PR, na francuskom govornom području se koristi naziv Relations publiques, italijanskom - Relazioni pubbliche i njemačkom - Oeffentlichkeitsarbeit (prema V. Sredanović, Javnost i mediji u Crnoj Gori, Obod, Cetinje, 2007, str. 15). Encikopedija Britannica pod terminom odnosi s javnošću definiše: ,aspekt komunikacije koji obuhvata promovisanje željenog imidža pojedinca ili grupe čiji je cilj da privuče pažnju javnosti“ (Encikopedija Britannica 1-10, knjiga 6, (2005) Beograd: Politika, Narodna knjiga, str. 101).

2 Slavujević, Z. (2005) Politički marketing, Beograd: Čigoja, Fakultet političkih nauka, str. 27.

3 Šiber, I. (1998) Osnove političke psihologije, Zagreb: Politička kultura, str. 180. 


\section{RADENKO ŠĆEKIĆ}

televizije, američki predsjednici njeguju običaj da se subotom obrate naciji posredstvom radija kao medija. ${ }^{4}$

Izvršioci same propagandne djelatnosti su stručnjaci za propagandu koji oblikuju propagandne poruke i tehničko osoblje koje omogućava da se propagandna poruka uputi preko nekog od sredstava informisanja do primaoca ali to su i spin doktori. Engleska reč spin znači okretati ili vrtjeti, pa je tako nastao izraz spin doctor - savjetnik za imidž, politički savjetnik ali i osoba izvještena i osposobljena za upravljanje informacijama i manipulacijom masovnim medijima; izraz spin control označava friziranje informacija, izjava za javnost, usmeravanje događaja i doziranje informacija. Spin doctoring se odnosi na niz aktivnosti: odbrana od novinara, odobravanje ili odbijanje intervjua, kao i podučavanje onih koji daju intervjue o tome šta da kažu i šta da ne kažu, kao i komentarisanje priča i pisanja novinara, ističući određene rečenice ili interpretacije. Spin doktori tvrde da oni samo „ubrzavaju“ proces širenja određenih vijesti i informacija. ${ }^{5}$

Spin doktori imaju puno dodirnih tačaka sa specijalnim savjetnikom za medije, osobom zaduženom za informisanje i odnose s javnošću. Spin-doktoring je umjetnost "spletkarenja" strategija odnosa sa javnošću, koja vijestima daje željeni smjer interpretacije. Pojam spin doktor se prvi put pojavio 1984. godine u Americi, tokom predsjedničke kampanje Reagan-Mondale, u članku Debata i spin doktori New York Times-a. ${ }^{6}$

Politički programi, političke izjave, izborne poruke, kampanje imaju političko značenje i, kako kaže B. McNair, ,efektnost im je samo onolika koliko se o njima izvještava i koliko ih medijska publika prima kao poruku". ${ }^{7}$ Prema tome, svi akteri političke komunikacije moraju doprijeti do medija ako žele prenijeti svoju političku poruku.

Poseban značaj u tome imaju agencije za odnose sa javnošću (public relations firm - PR) koji za izvjestan honorar zastupaju

4 Radio izvještavanje o događajima u izbornim kampanjama u SAD počinje 1924. ali je pokrivenost cjelokupnog biračkog tijela ostvarena tek 1932. godine. Prvi koji je koristio radio u kampanji je F. Ruzvelt. On je u vrijeme prve predsjedničke kampanje imao protiv sebe veći dio štampe, pa se njegova pobjeda nad Huverom, kao i kasniji reizbor, pripisuju i njegovom maestralnom korišćenju radija, Slavujević, Z. (2005) Politički marketing, Beograd: Čigoja, Fakultet političkih nauka, str. 139.

5 Street, J. (2003) Masovni mediji, politika i demokracija, Zagreb: Fakultet političkih znanosti, str. 4.

6 Sredanović, V. (2007) Javnost i mediji u Crnoj Gori, Cetinje: Obod, str. 19.

7 McNair, B. (2003) Uvod u političku komunikaciju, Zagreb: Fakultet političkih znanosti, str. 19. 


\section{RADENKO ŠĆEKIĆ}

interese određenog subjekta. ${ }^{8}$ Ove agencije koriste saznanja iz oblasti društvenih nauka, naročito psihologije i sociologije. Svoju pažnju usmjeravaju prema centrima moći. ${ }^{9}$ Takođe, u kampanji se koriste pored televizije i radija, i ostala sredstva, poput telefona (telemarketing, korišćen još 1960. u kampanji R. Nixona), film (biografski dokumentarci Regana, Buša, Klintona), internet ${ }^{10}$. Jedna od karakteristika političkog života SAD su i lobiji. ${ }^{11} \mathrm{~S}$ obzirom na složenost društva, široko proklamovana ljudska prava i slobode, moć i značaj medija i javnog mnenja, nepostojanje ideoloških razlika među glavnim političkim subjektima, persuazivno djelovanje karakterišu perfidnije i blaže forme. Primjena načela efikasnosti naročito je uočljiva tokom izbornih kampanja za kongres i tokom izbora za predsjednika,

8 „Prema Američkom ministarstvu pravde, Hrvatska je plaćala agenciji Ruder Fin 10.000 dolara mjesečno plus za rad na pozitivnom ugledu kod članova Kongresa SAD, administracije, u štampi i na TV.”, Tadić, M. (2002) Osnovi međunarodne propagande, Beograd: BINA, str. 88.

9 Tako direktor američke agencije za odnose sa javnošću Ruder Fin Global Public Affairs, Džems Harf ističe da je zadatak ovakve firme da ...prenosi priče subjekta propagande ljudima kojima ih treba prenijeti. Poznajemo moderne tehnike, znamo kako da stvorimo i šaljemo poruke, tako da ako želite da pobijedite, onda morate iznajmiti agenciju za odnose sa javnošću (M. Tadić, Osnovi međunarodne propagande, BINA, Beograd, 2002, str. 88). Uloga, dakle, ovakvih agencija se sastoji u tome da ubrzaju protok informacija, i da stvore razumijevanje i podršku objekta propagande, kao i da svojim savjetima i preporukama nalogodavaca, u vezi strategije i taktike komunikacionog pristupa, pomažu u pridobijanju javnog mnjenja a posebno politički uticajnih subjekata. Brzina je presudan činilac u postizanju željenog cilja, jer sve informacije koje teže njemu, moraju biti maksimalno brzo raspoređene u komunikacioni prostor, da bi izloženi stavovi i ideje prvi bili predstavljeni. Kako kaže pomenuti direktor Harf: Znamo savršeno dobro da je prva vijest važna. Demanti imaju mali efekat, Merlino, Ž. (1994) Istine o Jugoslaviji nisu sve za priču, Beograd, str. 95.

10 Iako su neki kandidati za pojedine političke funkcije u SAD već 1994. godine postavili web stranice, kao početak većeg korišćenja tog novog oblika političke komunikacije uzima se 1996. i završna rečenica u TV debati demokratskog kandidata za potpredsjednika, Boba Dola, usmjerena mlađim biračima: Tražim vašu podršku. Tražim vašu pomoć, i ako stvarno želite uključiti se u kampanju, dođite na moju Web stranicu www.dolekemp96.org. Neposredno nakon emisije, njegova stranica je zabilježila više od 2 miliona posjeta. Iste te godine, 50 miliona birača je posjetilo Web stranice $\mathrm{CNN}$-a kako bi saznali izborne rezultate, Šiber, I. (1998) Osnove političke psihologije, Zagreb: Politička kultura, str. 29.

11 Prema Oxfordskom rečniku, lobi je velika prostorija otvorena za javnost a lobiranje je obraćanje članovima parlamentarnog skupa u namjeri da se utiče na zakonodavstvo. To je djelovanje grupe za pritisak na postojeću vlast radi sprovođenja sopstvenih ideja i interesa. U SAD je lobiranje legalno samo ako se obavlja pri Kongresu (Senat i Predstavnički dom) a Foreign agent registration act posebnom postupku podvrgava lica koja se pojavljuju u svojstvu lobiste i nekog stranog zastupnika. Njihove obaveze su: 1. da se registruju pri skupštinskim pisarnicama; 2 . da sistematski saopštavaju određene informacije; 3. da među lobiste i strane koje zastupa budu upisani svi troškovi obavljenih aktivnosti, Klaman, M. (2004) Lobiranje, Beograd: Clio, str. 207. 


\section{RADENKO ŠĆEKIĆ}

karakterišu ga striktno određeni i vremenski ograničen cilj, sve veća specijalizacija i profesionalizacija i sve veći broj učesnika markentiških aktivnosti, estetizacija poruka i sl. Kao što kaže J. Street, ,političke vijesti su rijetko jednostavan proizvod političara i novinara, one su, u stvari, smicalice koje kreiraju mnogi posrednici“. ${ }^{12}$

PR, odnosi s javnošću, ne predstavljaju ništa ni novo ni spektakularno. Odnosi s javnošću su zanat, u okviru zanata. U ovom slučaju medijskog zanata i struke. To je sistematska, organizovana aktivnost $u$ cilju formiranja i održavanja svojevrsne percepcije i slike u javnosti. Uočljiva je izrazita dominacija PR-a $\mathrm{u}$ sferi informativnih sadržaja. Digitalna i internet revolucija u potpunosti je izmijenila medijsku scenu i način plasiranja informacija, ali i dovela u krizu mnoge stare i ustaljene novinarske profesije. Novinari, stručnjaci za odnose s javnošću, spin doktori su veoma upućeni jedni na druge. S obzirom da je najveći procenat informativnog dijela medijskog prostora ispunjen uglavnom PR materijalom, široke su mogućnosti njegove zloupotrebe, friziranja, manipulacije. Stručnjaci za kreiranje i oblikovanje informacijama su oni koji manipulišu javnošću i koji najčešće vladaju etrom i komunikacionim procesom. Razlika između PR-a i spinovanja je u tome, što se PR bazira, uglavnom, na informaciji i činjenicama, a spin na manipulaciji i trikovima. Spin doktor je osoba zadužena za oblikovanje povoljne percepcije javnosti o političarima ili političkoj stranci, vještim manipulisanjem masovnim medijima. Spin doktori poznaju tehnologiju rada medija, specifične karakteristike medija. Spin doktori zavise od medija, ali i mediji zavise o spin doktorima, jer imaju robu tj. informacije koje su medijima život. Upravo, iz takvog međusobno povezanog odnosa i kohabitacije spinova i medija dolazi do svojevrsnog pakiranja politike. ${ }^{13}$

Za spinovanje je karakteristično pažljivo biranje trenutka i načina za njegovo sprovođenje. Spinovanje je uvršteno u okvire djelatnosti odnosa sa javnošću i opisuje se kao oblik propagande koja se ostvaruje pružanjem interpretacije nekog događaja ili kampanjom, sa ciljem da se ubijedi javnost u korist ili protiv određene ideje, organizacije ili ličnosti. Neki od spin doktora postali su i sami zvijezde medija, poput Alastaira Campbella, bivšeg savjetnika britanskog premijera Tonyja Blaira, Marka McKinnona, - spin doktora američkog predsjednika Georga W. Busha i $P$. J. Mare, bivšeg savjetnika irskog premijera Bertiea

12 Street, J. (2003) Masovni mediji, politika i demokracija, Zagreb: Fakultet političkih znanosti, str.126.

13 Knežević, V. (2006) Spin doktori, Banja Luka: Litera, str. 20. 
Aherna, koji se proslavio i u Hrvatskoj kao spin doktor bivšeg predsjednika Ive Sanadera.

Protekle dvije decenije na prostoru Jugoistočne Evrope su bile veoma turbulentne $\mathrm{u}$ atmosferi ratova, ratnog okruženja, ekonomske, društvene i etičke krize. Iznjedrile su i kreirale brojna zanimanja (po ugledu na Zapad), u kojima su, bez kvalitetne obuke, obrazovanja i profesionalnih i etičkih standarda, mnogi sebi davali za pravo i slobodu da se, bez adekvatne podloge, samoproklamuju u svojevrsne multipraktik stručnjake, poput: političkih analitičara, sociologa religije, savjetnika sa imidž, ali i stručnjaka za odnose s javnošću (PR). Promjene društvenog uređenja, izmijenile su i značaj i ulogu medija, koji su doživjeli pravi bum. Nažalost, profesija PR-a ostala je uglavnom na ravni monologa i uniformnog gledanja na stvarnost jer, za razliku od ustaljenog novinarskog pravila da se piše i izvještava za šire narodne mase i za svu javnost, PR službe prave razliku i fokus, te stratifikuju uz divergenciju primaoce i konzumente informacija.

Naročito u oblasti političkog PR-a i u formi stranačkih medijskih pulova, službe za odnose s javnošću sprovode u djelo i za javnost odluke političkih elita koje se nalaze u drugom ili, ponekad, u trećem planu. Tokom predizbornih aktivnosti, uočljiv je nedostatak korektnosti i profesionalnosti u medijskom prostoru. U novinarskom prostoru, članku, analizi, nedostaje jasna razlika između oglasnog prostora i političkog marketinga. Time se informacije friziraju, spinuju, instrumentalizuju, a vijest postaje roba koju posjeduju interesne grupe i političke elite. Upravo to ističe Noam Čomski: ,uloga PR službi danas je potkopavanje demokratije. Samo informisani birači donose dobre odluke. Pogledajte izborne kampanje - cilj PR mašinerije je da stvori dezinformisane birače koji donose iracionalne odluke. PR industrija stigla je do politike prostom transformacijom iz svoje primarne funkcije - komercijalnog marketinga, a komercijalno oglašavanje je stvoreno da bi podrivalo tržište. Svako ko je učio ekonomiju zna da je slobodno tržište zasnovano na informisanim potrošačima koji donose racionalne odluke. Kada uključite televizor, vidite da su reklame stvorene da dezinformišu potrošače i navedu ih na iracionalne kupovine". ${ }^{14}$

Vraćanje profesionalnim i etičkim vrijednostima struke i provjerenoj, kvalitetnoj informaciji bi trebalo postati imperativ, jer medijska branša postaje funkcionalno sve složenija i komplikovanija.

14 Noam Čomski, specijalni gost Global media foruma, u organizaciji Dojče velea u Bonu, jun 2013. http://www.vijesti.me/svijet/noam-comski-pr-industrija-potkopava-demokratiju-clanak-134567 


\section{RADENKO ŠĆEKIĆ}

\section{LITERATURA:}

Sredanović, V. (2007) Javnost i mediji u Crnoj Gori, Cetinje: Obod Slavujević, Z. (2005) Politički marketing, Beograd: Čigoja, Fakultet političkih nauka

Encikopedija Britannica 1-10, knjiga 6, (2005) Beograd: Politika, Narodna knjiga

Street, Dž. Masovni mediji, politika i demokracija, Zagreb: Fakultet političkih znanosti

Knežević, V. (2006) Spin doktori, Banja Luka: Litera

McNair, B. (2003) Uvod u političku komunikaciju, Zagreb: Fakultet političkih znanosti

Tadić, M. (2002) Osnovi međunarodne propagande, Beograd: BINA

Merlino, Ž. (1994) Istine o Jugoslaviji nisu sve za priču, Beograd

Šiber, I. (1998) Osnove političke psihologije, Zagreb: Politička kultura

Klaman, M. (2004) Lobiranje, Beograd: Clio

Street, J. (2003) Masovni mediji, politika i demokracija , Zagreb:

Fakultet političkih znanosti

Knežević, V. (2006) Spin doktori, Banja Luka: Litera 


\title{
RADENKO ŠĆEKIĆ
}

\author{
Radenko Šćekić \\ University of Montenegro \\ POLITICAL PR, MEDIA AND \\ SPIN DOCTORING
}

\begin{abstract}
Along with political organizations and the citizens, the media are also participants in the political communication. The phenomena of the influence of the media and the influence on the media are obvious. Political stakeholders need to use the media in order to make sure that their messages are transmitted to the targeted public. So, in time, politicians become more and more of actors striving to present themselves to the public in their best possible light. The executors of the propaganda activities are not only propaganda experts who shape the propaganda messages but also the technical staff who ensure that the propaganda messages are transmitted to recipients through information technologies - they are spin doctors as well. "To spin" (to turn, to roll, to rotate), and so a "spin doctor" - an image consultant, a political consultant, but also a person who is skilled and trained to manage information and manipulate the mass media; spin control dressing of the information, public announcements, event directors and information dispensers. The term "spin doctoring" refers to a set of activities: defense of journalists, approval or disapproval of interviews, instructing those who give interviews on what to say or not to say, as well as commenting of the stories and journalists' writings and underlying specific sentences and interpretations. Spin doctors claim that they only accelerate the process of expanding specific news and information. Spin doctors have a lot in common with a special media councilor - a person in charge of media releases and public relations. Spin-doctoring is the art of "plotting" the strategies of public relations to give the news a desired direction of interpretation.
\end{abstract}

Key words: Political PR, public opinion, spin doctoring, media manipulation 